\title{
Participação cidadã no planejamento das ações da Emater-RN*
}

\author{
Jássio Pereira de Medeiros** \\ Djalma Freire Borges***
}

S UMÁRIO: Introdução; 2. A participação no processo decisório; 3. Antecedentes da Emater-RN; 4. Metodologia; 5. Resultados; 6. Conclusão.

Sum MARY: 1 . Introduction; 2. Participation in the decision-making process; 3. Emater-RN's antecedents; 4. Method; 5. Results; 6. Conclusion.

Palavras-chave: assistência técnica e extensão rural; agricultores familiares; participação cidadã; níveis de participação.

KEY WORDS: technical assistance and agricultural extension; small farmers; civil participation; participation levels.

Os serviços públicos de assistência técnica e extensão rural no país são desenvolvidos em espaço onde coexistem grupos sociais muito distintos, desde empresários do agribusiness até grupos tradicionais de agricultores familiares. Tendo como tema a participação dos agricultores familiares na elaboração das ações de assistência técnica e extensão rural, este artigo analisou o processo decisório participativo do planejamento 2005 da Emater$\mathrm{RN}$, utilizando como referência teórica principal a escada de participação cidadã de Arnstein (1969). Foi realizada uma pesquisa de campo, documental e bibliográfica, de tipo exploratório, com abordagem qualitativa, e os dados, coletados de diferentes fontes - entrevistas, observações não-participantes e documentos - foram submetidos à análise de conteúdo do tipo categorial

\footnotetext{
* Artigo recebido em fev. e aceito em set. 2006.

** Mestrando em administração pela UFRN. Endereço: Residência Universitária de Pós-Graduação, ap. 9, Campus Universitário UFRN — Lagoa Nova — CEP 59078-970, Natal, RN, Brasil.E-mail: jassiop@yahoo.com.br.

*** Doutor em administração, professor no Programa de Pós-Graduação em Administração da UFRN. Endereço: Av. Rodrigues Alves, 410, ap. 1100 - Petrópolis - CEP 59020-200, Natal, RN, Brasil. E-mail: dfb@digi.com.br.
} 
(Bardin, 1977). Os resultados evidenciaram que o nível de participação do agricultor no planejamento da instituição se encontra em uma situação intermediária entre uma participação simbólica e uma participação real. Essa busca contínua de aperfeiçoamento dos canais participativos é relevante, no sentido de que mais que a institucionalização, acredita-se que o aperfeiçoamento e a continuidade dos processos de gestão participativa dependem da relação, sempre tensionada e crescentemente qualificada, entre a sociedade organizada e o Estado.

\section{Citizen participation in Emater-RN's action planning}

Technical assistance and agricultural extension public services in Brazil are rendered in an environment where very distinct social groups — from agribusiness entrepreneurs to traditional small farmers - coexist. Having as theme the participation of small farmers in technical assistance and agricultural extension planning, this article analyzes the participatory decisionmaking process of Emater-RN's 2005 planning, using as main theoretical reference Arnstein's (1969) citizen participation ladder. An exploratory documental and bibliographical field research, with a qualitative approach, was performed, and the data collected from different sources - interviews, nonparticipant observations and documents - was submitted to a categorical content analysis (Bardin, 1977). Results evidenced that the level of participation by the farmer in the institution's planning is in an intermediary situation between token and real participation. This permanent quest to improve participatory channels is relevant since, beyond institutionalization, the improvement and continuity of the participatory management process depend on the relation, always tensioned and increasingly qualified, between the organized society and the state.

\section{Introdução}

Os serviços de assistência técnica e extensão rural no país foram iniciados no final da década de 1940, no contexto da política desenvolvimentista do pósguerra voltados à industrialização. Inicialmente implantados como uma atividade privada ou paraestatal, na década de 1970 foram "estatizados" pelo então presidente Ernesto Geisel. Em 1990 o governo Collor de Mello extinguiu o órgão nacional responsável pelos serviços de assistência técnica e extensão rural fazendo cair a participação financeira do governo federal em níveis financeiros.

Para caracterizar os elementos necessários de uma política voltada para o desenvolvimento rural, deve-se considerar a grande diversidade ambiental, socioeconômica e cultural existente no meio rural brasileiro, associada às pro- 
fundas desigualdades regionais. Coexistem nesse espaço grupos sociais muito distintos, desde empresários do agrobusiness até grupos tradicionais como ribeirinhos, extrativistas, pescadores, quilombolas e comunidades indígenas. Tal fato implica na possibilidade ou mesmo na necessidade da formulação, dentro desse tema, de políticas também diferenciadas, com estratégias, objetivos e públicos bastante distintos (Domingues et al., 2001).

Surge então, em 1995, relacionado à política de assistência técnica e extensão rural, o Programa Nacional de Fortalecimento da Agricultura Familiar (Pronaf), de nível federal, que articulado pela Secretaria de Agricultura Familiar, subordinada ao Ministério do Desenvolvimento Agrário, passa a atuar como uma espécie de divisor de águas no processo de intervenção estatal na agricultura e no mundo rural brasileiros.

Esse surgimento responde ao impacto de dois grandes vetores: de um lado, a pressão dos movimentos sociais em favor de transformações estruturais e da democratização das políticas públicas, e, de outro, o indiscutível reconhecimento do status científico da questão como categoria analítica por parte da intelectualidade brasileira (Anjos et al., 2004).

Dentro desse contexto, por exemplo, aparecem os princípios colocados pela Política Nacional de Assistência Técnica e Extensão Rural, formulada em 25 de maio de 2004, que devem ser seguidos pelas instituições prestadoras dos serviços de assistência técnica e extensão rural, sejam elas públicas (municipais, estaduais e federais), conveniadas com o setor público, organizações nãogovernamentais, redes e consórcios entre outras. Tais princípios foram assim estabelecidos:

v assegurar com exclusividade aos agricultores familiares, o acesso ao serviço de assistência técnica e extensão rural pública, gratuita, de qualidade e em quantidade suficiente;

v contribuir para a promoção do desenvolvimento rural sustentável;

v adotar enfoques metodológicos participativos e um novo paradigma metodológico pautado nos princípios da agroecologia;

v contribuir para a construção da cidadania e facilitar o processo de controle social no planejamento, monitorando e avaliando as atividades;

v desenvolver processos educativos permanentes e continuados, a partir de um enfoque dialético, humanista e construtivista. 
A Política Nacional de Assistência Técnica e Extensão Rural coloca assim que para dar conta dos desafios, os serviços públicos na área devem ser executados mediante o uso de metodologias participativas, devendo seus agentes desempenharem papel educativo, atuando como animadores e facilitadores de processos de desenvolvimento rural sustentável. Isso exige novas formas e instrumentos para relacionar os diversos atores e capacitá-los em gerenciar processos de desenvolvimento em conjunto.

Neste sentido, entende-se como premissa deste artigo que planejamento participativo é um instrumento que pode servir como fio norteador para tais processos, que exigem mudanças nas relações e nas posturas das pessoas envolvidas, tornando-se talvez o maior desafio de todos os processos de desenvolvimento.

Por isso, trata-se neste artigo do processo participativo utilizado na elaboração do planejamento das ações para o ano 2005 desenvolvido pelo Instituto de Assistência Técnica e Extensão Rural do Rio Grande do Norte (Emater-RN).

Após uma discussão teórica em torno da participação no processo de tomada de decisão é apresentada a instituição onde aconteceu o estudo. Depois são descritos os procedimentos metodológicos adotados durante a intervenção de campo. Os resultados do estudo explicitam a forma como é gerida a participação no processo decisório da organização estudada no que tange à forma como as ações estruturantes de assistência técnica e extensão rural entram na agenda da organização. Finalmente, a conclusão destaca o nível de participação cidadã detectado no processo de tomada de decisão da organização estudada.

\section{A participação no processo decisório}

A análise do comportamento de uma instituição de caráter público demanda, em primeira instância, o entendimento de como se dá o processo de tomada de decisão no seu interior. Dizer que este comportamento é determinado pelas motivações e ações das pessoas que de alguma forma influenciam este processo, embora seja evidente, não é suficiente para analisá-lo em profundidade, uma vez que suas características podem variar consideravelmente dependendo de uma série de fatores, em especial das características da própria instituição.

O fato de que a tomada de decisão — a formulação da política — é determinante dos demais momentos do processo de existência da política - implementação e avaliação - obriga uma abordagem com algum detalhe, se o 
objetivo é entender o comportamento de uma instituição e dos seus atores dominantes.

O processo de elaboração de políticas públicas costuma ser dividido, para fins heurísticos, em três fases sucessivas - formulação, implementação e avaliação - que conformam um ciclo que se realimenta.

Segundo essa divisão, a política é, primeiramente, formulada. Isto é, concebida no âmbito de um processo decisório, pelos "tomadores de decisão". Processo que pode ser democrático e participativo ou autoritário, com ou sem manipulação e controle da agenda dos atores com maior poder.

Por vezes, o esforço do governo para a criação de condições para a participação é muito restrito, de maneira que o processo carece de legitimidade. Não é simples definir, mesmo em termos operacionais, um conceito útil de participação popular na administração pública. Em sentido amplo, participar significa intervir num processo decisório qualquer (Modesto, 1999).

A participação pode ser definida como um instrumento fundamental no sentido de promover a articulação entre os atores sociais, fortalecendo a coesão da comunidade e melhorando a qualidade das decisões, tornando mais fácil atingir objetivos comuns. Todavia, é útil advertir que os métodos participativos não podem ser vistos como infalíveis e capazes de solucionar adequadamente todos os tipos de problemas (Manfredini e Lopes, 2005).

Assim é que Cunill (1991) destaca dois elementos-chave no conceito de participação: intervenção no curso de uma atividade pública e expressão de interesses sociais. A partir desses dois elementos, a autora faz a identificação dos fenômenos que não podem ser considerados como participação cidadã. Conclui que a participação cidadã não é uma alternativa à democracia representativa, mas apenas um complemento à mesma.

Em relação ao primeiro elemento, a autora esclarece que não devem ser considerados participação cidadã os seguintes fenômenos: a participação social, a participação comunitária e as experiências autônomas da sociedade civil. No caso da participação social, os indivíduos formam parte de organizações que nascem na sociedade para defender interesses sociais, e sua relação não é diretamente com o Estado, mas apenas com outras instituições sociais.

Em relação ao segundo elemento - expressão de interesses sociais - a participação cidadã só se circunscreveria à órbita dos interesses particulares radicados na sociedade civil, referidos especificamente a interesses difusos e coletivos. 
A participação, segundo a autora, implicaria a criação de novos caminhos ou novas relações entre a sociedade civil e a esfera pública, dependendo, assim, de quatro fatores:

、 níveis da participação - âmbito político e âmbito da gestão pública;

- caráter da intervenção dos cidadãos nas atividades e/ou órgãos públicos consultiva e/ou assessora, resolutiva e fiscalizadora e participação na execução;

v caráter dos sujeitos sociais intervenientes — indireto e direto;

、 origem do impulso à participação — implicação cidadã e ação cidadã.

Jacobi (1990), ao propor o conceito de "participação dos cidadãos", corrobora com Cunill (1991) em relação a um dos elementos apontados para esclarecer tal conceito, quando enfatiza que se trata de uma forma de intervenção na vida pública com uma motivação social concreta que se exerce de forma direta e de um método de governo baseado em um nível de institucionalização das relações Estado-sociedade.

O objetivo da participação é o de possibilitar o contato mais direto e cotidiano entre os cidadãos e as instituições públicas, para possibilitar que estas considerem os interesses e concepções político-sociais daqueles no processo decisório. Assim, a participação envolve uma conduta ativa dos cidadãos nas decisões e ações públicas, na vida da comunidade e nos assuntos de interesse das coletividades de que sejam integrantes.

É válido, portanto, conforme Carvalho (1998), analisar diferentes práticas do que se entende hoje no Brasil por participação, identificando seus limites e potencialidades em relação a algumas questões: até que ponto a participação social melhora efetivamente as condições de vida da população? Em que medida efetivamente democratiza a política e até que ponto fortalece o tecido social?

Arnstein (1969) considera a participação do cidadão como algo essencial para o exercício da cidadania. É a redistribuição do poder que permite aos cidadãos excluídos dos processos políticos e econômicos a oportunidade de deliberar sobre o futuro da sociedade.

Baseada na hierarquização de tipos de participação e não-participação a autora elaborou uma tipologia de oito níveis da participação. Para ilustrar os oito tipos são arranjados em um teste padrão da escada de participação cidadã (figura 1), com cada degrau correspondendo à extensão do poder dos cidadãos em determinar o resultado final na ação pública. 


\section{Escada de participação cidadã}

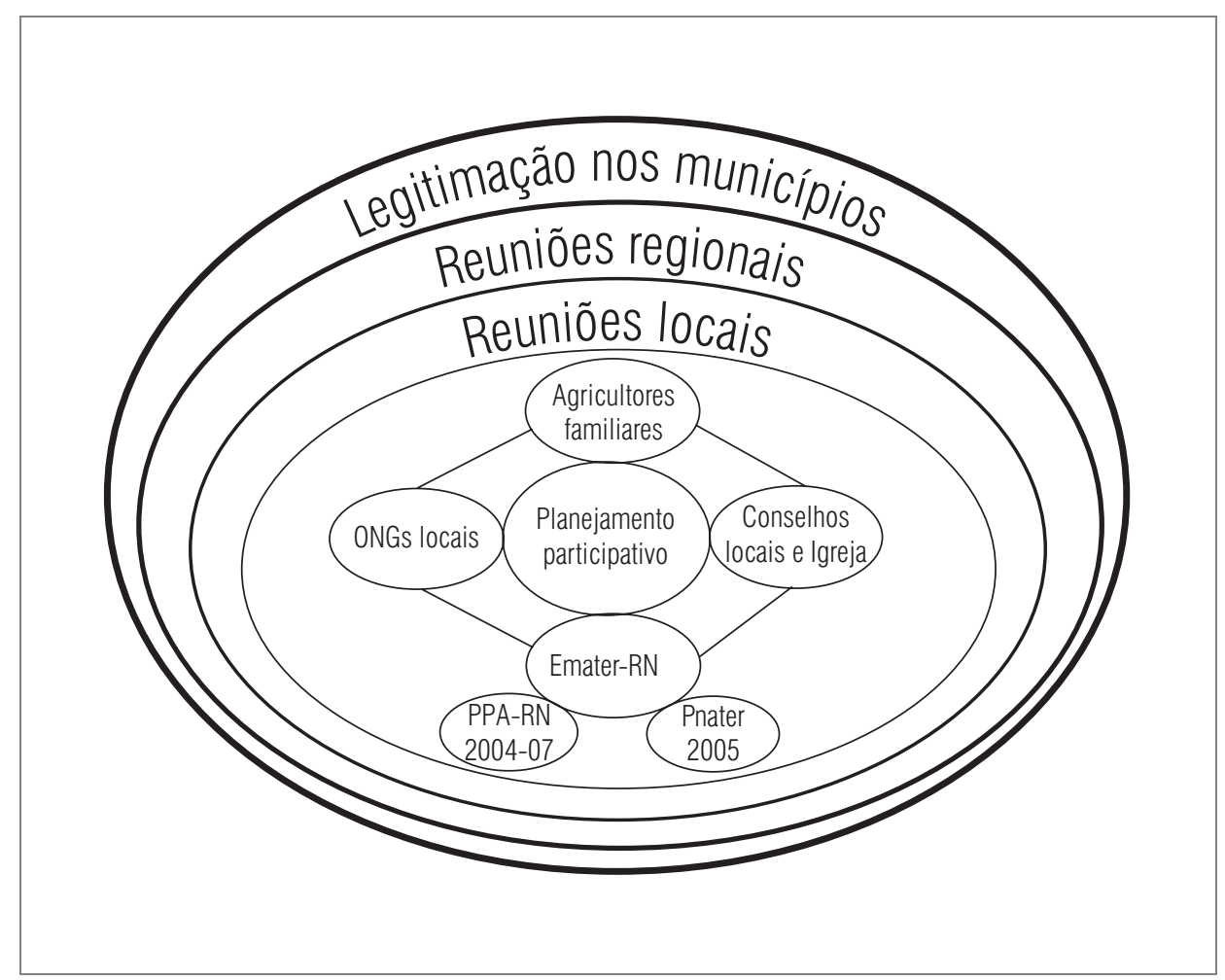

Os degraus inferiores da escada são manipulação e terapia. Eles descrevem os níveis de "não-participação" adotados para substituir uma participação genuína. Seu objetivo real não é permitir que as pessoas participem do planejamento ou em programas, mas que os detentores do poder manipulem os participantes. Nos degraus 3 e 4 - informação e consulta - os cidadãos podem ouvir e ser ouvidos. Mas sob tais circunstâncias faltam meios aos cidadãos para assegurar que seu ponto de vista chamará a atenção dos detentores de poder. Quando a participação é restringida a esses níveis, não há uma progressão, portanto nenhuma garantia de mudar o status quo. O degrau 5 pacificação - é simplesmente o nível mais elevado do simbolismo, visto que as regras permitem que os cidadãos recomendem, mas o poder de decidir continua retido nas mãos de poucos - powerholders - de acordo com denominação da autora. 
Subindo na escada o poder de decisão do cidadão vai crescendo. Os cidadãos podem participar de uma parceria (6), que os permita barganhar poder junto a seus detentores. Nos degraus mais altos da escada de participação, 7 delegação de poder - e 8 - controle do cidadão — os cidadãos obtêm a maioria de assentos da tomada de decisão, ou o poder administrativo completo.

Obviamente, os oito degraus da escada são uma simplificação, mas ajudam a ilustrar um ponto que muitos têm esquecido: que existem significativos graus para a participação do cidadão. Conhecer esses graus torna possível compreender as demandas cada vez mais fortes por uma participação dos cidadãos, tão bem quanto a gama de respostas desconcertantes dos detentores do poder.

Como limitação para essa escada, Arnstein (1969) enfatiza que, na realidade, nem os cidadãos nem os detentores do poder constituem blocos homogêneos. Deve-se notar que a tipologia não inclui uma análise dos caminhos mais significativos para conseguir níveis genuínos da participação. Um outro cuidado sobre os oito degraus separados na escada é que no mundo real das pessoas e dos programas, pode haver dezenas de degraus com distinções mais ou menos "puras" entre eles. Além disso, algumas das características usadas para ilustrar cada um dos oito tipos poderiam ser aplicáveis a outros degraus. Dentro desse contexto são explicitados os oito degraus de participação popular.

V Manipulação - tem como objetivo permitir que os detentores do poder possam educar as pessoas. Manifesta-se em conselhos nos quais os conselheiros não dispõem de informações, conhecimento e assessoria técnica independente necessários para tomarem decisões por conta própria.

- Terapia - os técnicos de órgãos públicos se escondem atrás de conselhos e comitês participativos para não assumirem erros cometidos por eles e diluir a responsabilidade.

V Informação - informar as pessoas sobre seus direitos, responsabilidade e opções. Entretanto, trata-se de um fluxo de informação somente de cima para baixo.

v Consulta - caracteriza-se por pesquisas de participação, reuniões de vizinhança, entre outros. Serve somente como fachada, não apresentando implicação prática.

- Pacificação - o cidadão começa a ter certo grau de influência nas decisões, podendo participar dos processos decisórios, contudo, não existe a obrigação dos tomadores de decisão de levar em conta o que ouviram. 
- Parceria - poder distribuído por uma negociação entre os cidadãos e detentores do poder. O planejamento e as decisões são divididos em comitês.

v Delegação de poder - cidadãos ocupando a maioria dos assentos nos comitês, com poder delegado para tomar decisões. Aqui os cidadãos têm poder sobre as contas da política pública.

v Controle do cidadão - cidadãos responsáveis pelo planejamento, pela política, assumindo a gestão em sua totalidade.

Por planejamento entende-se o cálculo que precede e preside a ação, possibilitando ao homem conduzir seu futuro e impor-se ao contexto por meio da razão. A complexidade dos problemas decorre da compreensão de que a produção social é gerada em um sistema humano que tem como características a historicidade, a complexidade, a indefinição e a incerteza. Portanto, não se aceita uma única explicação ou a predição do futuro, exigindo-se uma solução situacional, discutível e dependente dos interesses e da posição dos atores envolvidos (Laluna e Ferraz, 2003).

Nas organizações públicas as relações de conflito e de articulação entre as forças sociais são mais intensas, o que requer uma tecnologia de planejamento que consiga propiciar o enfrentamento dos problemas e a obtenção de soluções criativas. Surge, então, o planejamento participativo como um instrumento para o trabalho comunitário. Por meio de discussões e exercícios que auxiliam a ampla compreensão de uma realidade, analisa-se um problema central e as propostas para solucioná-lo, resultando na elaboração de um plano de ação para combatê-lo.

A participação conjunta dos moradores, comitês, instituições governamentais e não-governamentais, segundo Bezerra, Santos e Silva (2001), cria elos que promovem compromissos sociais. Os três grandes eixos de um projeto social são: seu planejamento (processo decisório), sua implementação e avaliação. Não distribuídos de forma linear, eles se inter-relacionam e ocupam diferentes espaços e tempos na construção desse projeto, assumindo, cada um a seu tempo, o lugar de destaque.

$\mathrm{O}$ ato de planejar permite a avaliação da situação como um todo, aumentando a possibilidade de prever as dificuldades e os modos para superálas. O planejamento aumenta nossa compreensão do trabalho a ser realizado, permite ver sua complexidade e suas dependências. Também é facilitador da comunicação grupal, pois mostra o papel de cada um dos atores envolvidos no processo, o que cada um pensa e qual será o modo de ação, gerando assim compromissos e responsabilidades mútuas. 
Segundo Demo (1996, apud Bezerra, Santos e Silva, 2001), são três os componentes básicos do planejamento participativo:

v formação de consciência crítica e autocrítica da comunidade, pela qual se elabora o conhecimento adequado dos problemas que afetam o grupo. A comunidade formula, com seu saber e em consórcio com o saber técnico, um posicionamento crítico diante da realidade;

v identificação e priorização dos problemas, formulando estratégias concretas de seu enfrentamento e encontrando caminhos alternativos e propostas de negociação;

$\checkmark$ a organização do grupo como estratégia para os dois passos anteriores.

Saliente-se que não há a pretensão de esgotar os limites da abrangência dos assuntos aqui abordados, principalmente por se tratar de temáticas cujo paradigma tem sido repensado em função das novas abordagens das teorias organizacionais que comportam noções e conceitos tais como: comportamento, mudança, processo, poder, complexidade, contexto, negociação, interconexão.

\section{Antecedentes da Emater-RN}

A extensão rural atua no Brasil há mais de 50 anos e desde o seu início tem como princípio o atendimento aos pequenos e médios agricultores, suas famílias e as organizações representativas, tais como associações, cooperativas, conselhos, entre outras.

No Rio Grande do Norte o serviço oficial de assistência técnica e extensão rural surgiu no ano de 1955, com a Associação Nordestina de Crédito e Assistência Rural (Ancar) tendo como municípios pioneiros Santa Cruz, São Tomé, São Paulo do Potengi e Currais Novos, atuando sob a coordenação regional sediada em Recife.

Em 1963, a extensão rural no Rio Grande do Norte já contava com 10 escritórios locais, 14 técnicos e 16 funcionários administrativos, que eram coordenados em nível nacional pela Associação Brasileira de Crédito e Assistência Rural (ABCAR) entidade que existiu até 1974.

A partir desse ano o sistema de extensão rural, com abrangência nacional, tomou um novo e decisivo rumo. Foram extintas a ABCAR e a Ancar e instituída a Empresa Brasileira de Assistência Técnica e Extensão Rural (Embrater). Como conseqüência da extinção da Ancar foi criada no Rio Grande 
do Norte a Emater, como entidade pública de direito privado, através da Lei Estadual no 484/75 e vinculada à Secretaria de Estado de Agricultura, da Pecuária e da Pesca (Sape).

Em meados da década de 1980, com o advento da Nova República e a implantação do novo modelo de reforma administrativa calcada na ideologia neoliberal do "Estado mínimo", inicia-se o processo de desmonte do serviço de extensão rural, consolidando-se no ano de 1990, no governo Collor de Mello, comprometendo a qualidade da política de assistência técnica e extensão rural em todas as entidades da federação.

Com a extinção da Embrater, a Emater-RN transforma-se em autarquia pela Lei $\mathrm{n}^{\mathrm{O}}$ 6.486, de 5 de outubro de 1993, aprovada pela Assembléia Legislativa, passando a se chamar Instituto de Assistência Técnica e Extensão Rural do Rio Grande do Norte (Inatern) vinculado à Sape, com competência para executar a política de assistência técnica e extensão rural no estado, com atividades voltadas para agricultura, pecuária, saúde e agroindústria. Hoje, a antiga Emater-RN tem em seu quadro funcional um total de 466 servidores, atuando em 154 municípios, sob a coordenação de 101 escritórios locais, 10 unidades regionais e um escritório central sediado em Natal.

\section{Metodologia}

O tipo de pesquisa utilizado, quanto aos meios, foi o estudo de caso, por tratar-se de trabalho que investiga um fenômeno contemporâneo, em um contexto real particular, em que os limites entre o fenômeno e o contexto não estão claramente definidos (Yin, 2001).

A pesquisa foi desenvolvida junto ao Instituto de Assistência Técnica e Extensão Rural do Rio Grande do Norte (Inatern), popularmente conhecido como Emater-RN, e o objeto de análise foi o processo decisório da instituição, no sentido de identificar o caráter da participação dos agricultores nas suas ações de planejamento. A perspectiva temporal é seccional com avaliação longitudinal, que consiste em investigar fenômenos ocorridos ao longo de um período, porém com dados coletados em um determinado momento. $\mathrm{O}$ processo decisório analisado ocorreu durante os meses de outubro e novembro de 2004, período durante o qual foi definido o planejamento da EmaterRN para o ano de 2005.

Os procedimentos necessários à obtenção de dados envolveram a combinação de formas de coleta, recorrendo-se a documentos, observações e entrevistas, que são fontes de evidências para estudos de caso. Especificamente para pesquisas sobre processos decisórios, Schwenk (1985) entende que se devam combinar diferentes tipos de fontes de dados. Além da necessidade de 
triangulação na análise e interpretação dos dados, motivaram a diversidade de fontes os seguintes aspectos: risco de imprecisão nos dados sobre política, comumente tratados com reserva nas organizações (Etzioni, 1989; Morgan, 1996); impossibilidade de entrevistas e documentos conterem informações sobre ações que não tenham sido acompanhadas de decisões explícitas e sobre qualquer decisão não tomada, ignorada ou esquecida (Hendry, apud Bin, 2005); e possibilidade de que nas entrevistas sobre processos decisórios os indivíduos enviesem, simplifiquem (Schwenk, 1985) ou racionalizem decisões (Shafir, Simonson e Tversky, apud Bin, 2005).

Os documentos consultados foram comunicações internas e a formalização do planejamento da instituição. As observações diretas não-participantes se deram em três das cinco reuniões do processo de planejamento. Os entrevistados foram selecionados intencionalmente, buscando identificar sujeitos que possuíssem, a priori, as características específicas da amostra. Em pesquisas qualitativas, por razões práticas, a amostra é geralmente reduzida, devendo adequar-se aos objetivos de acordo com o "processo social em exame" (the social process under scrutiny) (Manson, 1996).

Em síntese, na definição de uma amostra intencional não interessa saber se a amostra é estatisticamente representativa da população, devendo prevalecer o princípio de que o tamanho do grupo pesquisado auxilia o pesquisador a compreender a temática em estudo. Para isso, optou-se por indivíduos com ativa participação no processo estudado e que se dispuseram a conceder entrevista.

Foram entrevistados três integrantes da Emater-RN: o diretor técnico; um membro da Coordenadoria de Planejamento e Execução, setor responsável pela articulação do planejamento da organização; e um funcionário alheio à articulação do planejamento participativo, mas lotado no programa de qualidade de vida da instituição. As entrevistas foram realizadas no próprio ambiente de trabalho da Emater-RN, no período de 24 a 28 de outubro de 2005, obedecendo a roteiro previamente elaborado pelos pesquisadores.

Os dados obtidos foram submetidos à análise de conteúdo do tipo categorial temática, para identificar unidades de significação isoláveis — temas (Bardin, 1977). Esse procedimento é coerente com o objetivo da pesquisa e com o método de coleta de dados uma vez que, segundo Bardin (1977), o tema é utilizado como unidade de registro quando o estudo envolver opiniões, atitudes e crenças, bem como quando os objetos de análise forem respostas a questões abertas, entrevistas ou reuniões de grupos.

No sentido de delimitar e orientar a parte empírica do trabalho foram utilizadas as seguintes categorias analíticas: os fatores de participação de Cunill (1991), a escada de participação cidadã, proposta por Arnstein (1969) e 
os componentes básicos do planejamento participativo colocados por Demo (1996).

A exposição dos resultados da investigação privilegia a fala e o sentimento dos atores a partir das próprias palavras e expressões verbalizadas. Esse procedimento metodológico expõe os fatos manifestados e destaca valores e representações externados pelos atores.

\section{Resultados}

O presente estudo buscou analisar o processo decisório de uma instituição estadual de assistência à agricultura familiar (Emater-RN) no que tange ao caráter de participação dos agricultores beneficiados no planejamento anual da organização. Para tanto foram trabalhados aspectos relacionados aos fatores de participação (Cunill, 1991), à escada de participação cidadã, proposta por Arnstein (1969) e aos componentes básicos do planejamento participativo colocados por Demo (apud Bezerra, Santos e Silva, 2001).

$\mathrm{Na}$ análise da metodologia do planejamento elaborado pela Emater$\mathrm{RN}$, verificou-se que a organização utilizou metodologias participativas em consonância com as orientações da Política Nacional da Assistência Técnica e Extensão Rural, para possibilitar aos agricultores e suas famílias transformarem-se em sujeitos do seu processo de desenvolvimento, valorizando os distintos saberes e o intercâmbio de experiência que permitam a ampliação da cidadania e inclusão social.

Como preparação para o planejamento organizacional foram feitos estudos preparatórios, orientados por um consultor externo, para a equipe da instituição que iria comandar o processo. Em seguida treinamentos foram realizados com os técnicos da instituição no intuito de repassar a metodologia a ser usada no trabalho com agricultores familiares. Elaborou-se, logo após, uma matriz técnica com variáveis qualitativas que norteariam o trabalho junto aos agricultores. A ida ao campo, isto é, o encontro entre os técnicos representantes da Emater-RN e os agricultores familiares, foi desenvolvida com um processo modular e permanente, a partir de reuniões nas comunidades rurais de cada município assistido pela organização (2.172 comunidades atendidas em 154 municípios) construindo o conteúdo e as práticas a serem realizadas. Importante destacar que dessas reuniões participavam também organizações não-governamentais da localidade, a Igreja e sindicatos, entre outras.

Aqui, Anjos e outros (2004) argumentam que a busca pelo fortalecimento do tecido social, identificando e qualificando as organizações populares autônomas e outros atores da sociedade civil - como igrejas, grupos culturais, 
clubes, entidades profissionais - como sujeitos promotores da cidadania, garante a continuidade, a permanência e o aperfeiçoamento da democracia participativa, uma vez que prioriza práticas menos dependentes da iniciativa governamental.

Os métodos de extensão rural, individuais, grupais e massivos foram desenvolvidos para possibilitar que os beneficiários se manifestassem em relação aos objetivos da ação extensionista e aos resultados alcançados. Destacaram-se os seguintes métodos: cursos, oficinas, seminários, excursões, intercâmbios, campanhas, clínicas tecnológicas, torneios leiteiros, dias de campo, feiras e exposições, fóruns e reuniões.

Após a fase de discussão das ações juntamente com os agricultores familiares foram realizados cinco encontros, um para cada duas unidades regionais, das 10 existentes na instituição. Esses encontros contaram com a participação dos diretores da organização, dos coordenadores técnicos do planejamento, dos representantes regionais e do consultor externo. Nesse momento foram sintetizadas e organizadas as demandas colocadas pelos agricultores de forma a montar o planejamento anual da instituição para o ano de 2005.

Discutidas as ações, conforme os métodos descritos, os resultados ainda seguiram uma fase de legitimação, consoante propõe Modesto (1999). Nessa fase as ações a serem trabalhadas na comunidade eram apresentadas a organizações formais dos municípios, tais como câmaras de vereadores e sindicatos de trabalhadores rurais.

Esse trabalho de ação/intervenção seguiu uma abordagem holística e um enfoque sistêmico, articulando o local, a comunidade e/ou território, possibilitando a geração e a socialização do conhecimento, utilizando técnicas vivenciais, estabelecendo relação entre teoria e prática, propiciando a construção coletiva dos saberes, intercâmbio de conhecimentos e o protagonismo dos atores na tomada de decisão.

Partindo para a análise da participação dos agricultores no planejamento 2005 da Emater-RN, foi possível identificar quatro fatores no processo decisório que, segundo Cunill (1991), implicariam a criação de novos caminhos ou novas relações entre a sociedade civil e a esfera pública. O primeiro deles seria a participação no âmbito da gestão pública, seguido de um caráter de intervenção resolutivo e fiscalizador (avaliação e monitoramento), e do envolvimento dos sujeitos diretamente beneficiados pela ação em discussão.

A Emater-RN avalia o nível de satisfação dos clientes internos e externos com monitoria e avaliação em sistema, apoiado com base nos seguintes procedimentos: oficinas técnicas com equipes locais, assessores técnicos e coordenadores regionais para encaminhamentos e avaliação das atividades pro- 
postas; sistematização das ações informatizadas enviadas com relatos das atividades; análise qualitativa do público beneficiário pelos conselhos e outros fóruns de gestão social; reuniões quinzenal, mensal e bimensal de monitoramento, avaliação e encaminhamentos dos trabalhos nas diversas áreas de extensão rural.

Esses encontros servem para avaliar e analisar os resultados obtidos e para socializar os assuntos tratados por ocasião das supervisões técnicas realizadas no campo, contando com a participação de todos os profissionais de assistência técnica e extensão rural, já que é entendido que a avaliação participativa inclui consulta a equipes, aos dirigentes, às entidades e organizações envolvidas, às partes interessadas e, finalmente, aos usuários/beneficiários dos projetos, ou seja, os agricultores familiares.

A origem do impulso para participação (quarto fator), no entanto, veio da ação cidadã no nível nacional, pela pressão de movimentos sociais (Domingues et al., 2001), e não dos agricultores atendidos no espaço estadual.

Quanto à análise do planejamento da organização de acordo com a escada de participação proposta por Arnstein (1969), observou-se que o processo apresenta características constantes nos degraus cinco e seis - pacificação e parceria. O poder decisório está distribuído entre cidadãos e detentores do poder (Emater-RN). Todavia, apesar da influência na tomada de decisão sobre quais ações de assistência técnica e extensão rural serão trabalhadas na localidade, não existe uma obrigatoriedade da instituição de levar em conta o que ouviram, já que a execução das ações está condicionada ao levantamento de recursos junto aos parceiros da instituição.

Um outro fator que pode comprovar a localização do planejamento da Emater-RN na escada de participação concebida por Arnstein é que nem todas as ações a serem realizadas na comunidade foram demandadas pelos agricultores. Em alguns casos a ação pode ter sido determinada pelas diretrizes nacionais da política de assistência técnica e extensão rural ou pelo Plano Plurianual (2004-07) do governo do Rio Grande do Norte. Quando da ocorrência de tal fato a proposta de ação da instituição era apresentada e esclarecida para os agricultores, uma vez que grande número deles possuía baixo nível de escolaridade e, ao mesmo tempo, não tinha conhecimento sobre as novas formas de negócios rurais.

Constatou-se também o que foi exposto por Demo (apud Bezerra, Santos e Silva, 2001), no sentido de que, por meio da organização de um grupo, é que ocorrem a constituição de um conjunto de representações da comunidade agrícola acerca dos problemas que a afetam, a determinação das características de um problema, a articulação de estratégias para seu enfrentamento e, por fim, a proposição de alternativas de negociação. 
Assim, a participação no planejamento institucional da Emater-RN se encontra entre o nível mais elevado do simbolismo de participação, no qual o cidadão recomenda mas o poder continua detido nas mãos dos responsáveis pela implementação, e o primeiro nível do que seria uma participação real, quando o cidadão passa a barganhar poder junto a seus detentores.

Baseado no encontrado a partir do presente estudo foi elaborado um diagrama representativo do que seriam as esferas do planejamento participativo da Emater-RN, no qual têm participação diversos atores sociais - entre os quais os agricultores familiares - sendo as ações da Emater-RN balizadas pelo Plano Plurianual do Rio Grande do Norte (PPA-RN) e pelo Plano Nacional de Assistência Técnica e Extensão Rural (Pnater), como evidenciado na figura 2.

\section{Conclusão}

A instituição estudada está inserida em um contexto no qual as opiniões se dividem em torno dos avanços obtidos pela Política de Assistência Técnica e Extensão Rural. De um lado, aqueles que manifestam a opinião de que ela está conseguindo produzir o ambiente institucional necessário à ampliação da base social da política nacional de crédito e desenvolvimento rurais. De outro, os que a criticam com base no caráter contraditório de uma política que enfatiza o desenvolvimento local e a potencialização de atividades diversificadas — industrialização, turismo, lazer etc. - mas paradoxalmente insiste na ênfase à profissionalização e apoio ao "verdadeiro agricultor", entendido como aquele produtor cujos rendimentos originam-se essencialmente na agricultura.

Partindo da análise dos dados de pesquisa, foi possível constatar que há um discurso institucional bem estruturado, no que se refere à participação cidadã no planejamento, como base para o desenvolvimento das ações da organização. Entretanto, quando se analisa a pertinência e a suficiência do caráter participativo no processo de planejamento institucional, tendo por base esse discurso e o aparato legal existente, constatam-se alguns limites.

Por um lado, há o limite relativo à existência ou não de parceiro com recursos para o desenvolvimento das ações. Por outro, as ações colocadas de cima para baixo pelas diretrizes da Política de Assistência Técnica e Extensão Rural e de seus pontos de atuação, constantes do Plano Plurianual 2004-07, do governo do Rio Grande do Norte.

Por isso o nível de participação do agricultor no planejamento da organização se encontra em uma situação intermediária entre participação simbólica e participação real, situando-se, conforme foi indicado anteriormente, nos degraus cinco (pacificação) e seis (parceria), na escada de participação de Arnstein (1969). 
Figura 2

Diagrama do planejamento participativo da Emater-RN

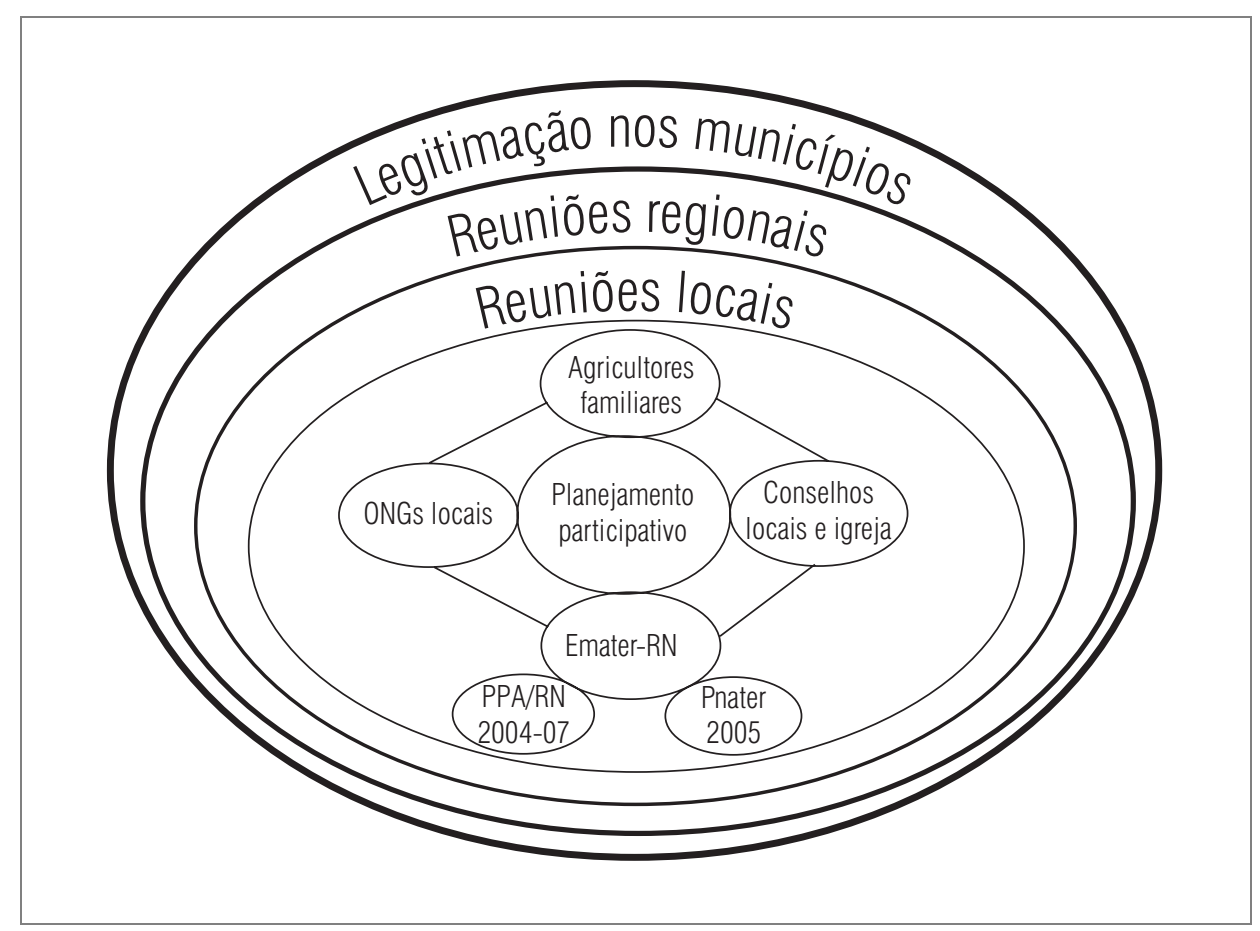

É importante a ampliação da eficiência e da eficácia dos espaços de gestão participativa, rompendo com a burocracia estatal e com a tendência de limitar a participação aos assuntos periféricos, dispersando-a em inúmeros espaços de um "conselhismo" segmentado.

Essa busca contínua de aperfeiçoamento dos canais participativos é relevante, no sentido de que mais que a institucionalização, acredita-se que o aperfeiçoamento e a continuidade dos processos de gestão democrática e participativa dependem da relação, sempre tensionada e crescentemente qualificada, entre a sociedade organizada e o Estado.

\section{Referências bibliográficas}

ANJOS, F. S. et al. Agricultura familiar e políticas públicas: o impacto do Pronaf no Rio Grande do Sul. RER, Rio de Janeiro, v. 42, n. 3, p. 529-548, jul./set. 2004. 
ARNSTEIN, S. R. A ladder of citizen participation. Journal of the American Planning Association, v. 35, n. 4, p. 216-224, July 1969.

BARDIN, L. Análise de conteúdo. 3. ed. Lisboa: Edições 70, 1977.

BEZERRA, R.; SANTOS, H. S.; SILVA, N. D. Utilização do diagnóstico participativo e organização social dos artesãos do distrito de Caraibeiras/Tacaratu-PE: relato de experiência do Programa Universidade Solidária/Xingó e UFRPE-2000. In: SEMINÁRIO DE METODOLOGIA PARA PROJETOS DE EXTENSÃO, 4., 2001, São Carlos. Anais Eletrônicos...

BIN, D. Comportamento político nas organizações: estudo sobre interesses particularistas em processo decisório. In: ENCONTRO ANUAL DA ANPAD, 29., Brasília, 2005. Anais... Brasília: Anpad, 2005.

CARVALHO, M. C. A. A participação social no Brasil hoje. 1999. Disponível em <www.polis. org.br/publicacoes/papers/19982>. Acesso em: 28 set. 2005.

CUNILL, N. Participación ciudadana. Dilemas y perspectivas para la democratización de los Estados Latinoamericanos. Caracas: Clad, 1991.

DOMINGUES, A. P. et al. Elementos para uma política de desenvolvimento rural com base na agricultura familiar - a inserção do Pronaf no PPA 2000-2003. Revista do Serviço Público, n. 2, abr./jun. 2001.

EISENHARDT, K. M. Building theories from case study research. Academy of Management Review, Briarcliff Manor, v. 14, n. 4, p. 532-550, Oct. 1989.

EMATER-RN. Plano anual de trabalho 2005. Natal: Emater-RN, 2005.

ETZIONI, A. Humble decision making. Harvard Business Review, Boston, v. 67, n. 4, p. 122126, July/Aug. 1989.

JACOBI, P. Descentralização municipal e participação dos cidadãos: apontamentos para o debate. Revista Lua Nova, n. 20, p. 121-143, maio 1990.

LALUNA, M. C.; FERRAZ, C. A. Compreensão das bases teóricas do planejamento participativo no currículo integrado de um curso de enfermagem. Revista Latino-Americana de Enfermagem, v. 11, n. 6, p. 771-777, nov./dez. 2003.

MANFREDINI, C.; LOPES, J. R. Participação comunitária em projetos de desenvolvimento local: um estudo no bairro de Marins, Piquete/SP. In: ENCONTRO ANUAL DA ANPAD, 29., Brasília, 2005. Anais... Brasília: Anpad, 2005.

MANSON, J. Qualitative researching. Londres: Sage, 1996.

MODESTO, P. Participação popular na administração pública — mecanismos de operacionalização. 1999. Disponível em <www.apoema.adv.br/participacao-popular-na-administ>. Acesso em: 28 set. 2005.

Rap Rio de Janeiro 41(1):63-81, Jan./Fev. 2007 
MORGAN, G. Imagens da organização. São Paulo: Atlas, 1996.

POLÍTICA NACIONAL DE ASSISTÊNCIA TÉCNICA E EXTENSÃO RURAL. Brasília: MDA/ SAF, 2004.

RIO GRANDE DO NORTE. Secretaria de Estado do Planejamento e das Finanças. Plano Plurianual - 2004/2007. Natal: Assecom, 2004.

SCHWENK, C. R. The use of participant recollection in the modeling of organizational decision processes. Academy of Management Review, Briarcliff Manor, v. 10, n. 3, p. 496-503, July 1985.

SOUZA, C. Estado do campo da pesquisa em políticas públicas no Brasil. Revista Brasileira de Ciências Sociais, v. 18, n. 51, 2001.

TENÓRIO, F. G.; COSTA, F. L. Bases conceituais e metodológicas para o estudo da participação cidadã na gestão pública: entre práticas e representações sociais. Rio de Janeiro: FGV, 1998.

YIN, R. K. Estudo de caso: planejamento e métodos. 2. ed. Porto Alegre: Bookman, 2001. 